\title{
Evaluasi Model Penerimaan pada E-Commerce Menggunakan Metode TAM
}

\author{
John Reimon Batmetan, Calvin Kumajas, Dwiputri Pusung, Michella Undap \\ Program Studi Teknik Informatika Universitas Negeri Manado, Tondano, 95618 \\ john.reimon@gmail.com.chalvin.kumajas@gmail.com,dwiputripusung26@gmail.com,michellaaundap@gmail.com
}

\begin{abstract}
ABSTRAK
Teknologi informasi telah memberi dampak bagi kehidupan manusia, termasuk bisnis dalam internet, yaitu E-Commerce yang menghemat waktu dan tidak memerlukan modal besar untuk mempromosikan produk. Tujuan penelitian ini adalah melakukan evaluasi tingkat penerimaan pada e-commerce sebagai sumbangan pemikiran bagi pihak Tokopedia sebagai motivasi dan dorongan untuk melakukan perubahan dalam sistem agar penerimaan teknologi semakin meningkat dan dapat mereka manfaatkan. Penelitian ini menggunakan metode TAM sebagai acuan untuk mengevaluasi tingkat penerimaan teknologi pada sistem e-commerce oleh para pengguna sistem atau pun seluruh masyarakat. Hasil penelitian ini menunjukan bahwa pengguna Sistem E-Commerce mayoritas setuju jika sistem E-Commerce ini membantu mereka. Hasil penelitian ini juga menunjukan bahwa e-commerce wajib memperhatikan minat,persepsi kegunaan,persepsi dan kemudahan penggunaan dalam menerapkan dan mengembangkan system informasi berbasis e-commerce.
\end{abstract}

Keywords : E-Commerce, Technology Acceptance Model, minat, persepsi, usability

\section{PENDAHULUAN}

Saat ini perkembangan teknologi informasi sangat kompleks dan memberi banyak dampak bagi kehidupan manusia, termasuk bisnis dalam internet, yaitu E-Commerce yang menghemat waktu dan tidak memerlukan modal besar untuk mempromosikan produk. Salah satunya adalah website Tokopedia yang melayani penjualan barang dan jasa sehingga siapa saja dapat berbisnis dan bersaing dengan biaya rendah. Dilansir dari Asian Nikkei Review, Indonesia mengalami pertumbuhan konsumen ecommerce sebesar 11 juta sepanjang 2017. Jumlah ini membuat total konsumen e-commerce menjadi 35 juta.

Survei yang dilakukan FT Confidential Research (FTCR) terhadap 1.000 konsumen perkotaan memperlihatkan ecommerce lokal yakni Tokopedia masih menjadi 'tuan di rumah sendiri. Kenyataanya di Indonesia pengguna e-commerce terhadap Tokopedia memilki persepsi kemudahan pengguna (percieved ease of use) yaitu mempunyai kepercayaan/ merasa percaya bahwa sistem informasi dari tokopedia mudah digunakan sehingga Tokopedia paling banyak digunakan dan saat ini sedang merajai e-commerce di tanah air. Sebagai salah satu contoh online-shopping yang cukup berhasil di Indonesia, forum ini dapat dijadikan acuan bagi para wirausaha lain yang ingin turut terjun ke dalam bisnis ini. Namun, untuk menguji lebih jauh tentang faktor-faktor apa saja yang berpengaruh pada penerimaan bisnis onlineshopping ini di Indonesia, diperlukan sebuah penelitian lanjutan. [1]

Permasalahan yang timbul adalah masih banyak masyarakat di Indonesia sebenarnya masih ragu akan pembelian barang atau jasa di internet,karena mereka menganggap sangat rawan akan penipuan padahal tidak semua jual beli online itu bisa ditipu. Memiliki kendala saat bertransaksi,contohnya: respon yang lambat dari toko pada pembeli untuk pemesanan dan mengkonfirmasi produk, gambar yang ditampilkan seringkali tidak sesuai dengan pesanan,dll.

Davis (1989) pada saat mengenalkan model Technology Acceptance Model (TAM) mengindikasikan penggunaan system sebagai indikator penting penerimaan suatu teknologi. Model 
awal TAM menggunakan kemudahan pemakaian persepsian dan kegunaan persepsian. [2]

Alasan atau tujuan penelitian ini dibuat adalah untuk sumbangan pemikiran bagi pihak tokopedia sebagai motivasi dan dorongan untuk melakukan perubahan dalam penerimaan e-commerce yang dapat mereka manfaatkan di bidang pemasaran.

\section{LITERATUR REVIEW}

\section{E-Commerce}

Menurut McLeod, e-commerce adalah penggunaan jaringan komunikasi dan komputer untuk melaksanakan proses bisnis[4]. E-commerce memiliki manfaat yang sangat besar. Pertama, para konsumen tidak perlu datang ke toko penjual untuk memilih barang yang ingin dibeli. Kedua, dari segi keuangan konsumen dapat menghemat biaya yang dikeluarkan, apabila lokasi toko jauh, konsumen dapat menghemat ongkos perjalanan dengan diganti biaya pengiriman yang jauh lebih murah.danbermanfaat oleh para pengguna, maka dapat dilihat bahwa penerapanteknologi informasi yang baru itu dapat diterima oleh pengguna [4].

\section{Komponen E-Commerce}

E-commerce memiliki beberapa komponen standar yang dimiliki dan tidakdimiliki transaksi bisnis yang dilakukan secara offline, yaitu (Hidayat, 2008:7) [4]

- Produk: Banyak jenis produk yang bisa dijual melalui internet sepertikomputer, buku, musik, pakaian, mainan, dan lain-lain.

- Tempat menjual produk (a place to sell): tempat menjual adalahinternet yang berarti harus memiliki domain dan hosting.

- Cara menerima pesanan: email, telpon, sms dan lain-lain.

- Cara pembayaran: Cash, cek, bankdraft, kartu kredit, internet payment (misalnya paypal).

- Metode pengiriman: pengiriman bisa dilakukan melalui paket, salesman, atau didownload jika produk yang dijual memungkinkan untuk itu (misalnya software).
- Customer service: email, formulir online, FAQ, telpon, chatting, dan lain-lain.

Pengguna E-Commerce

Penggolongan e-commerce yang lazim dilakukan orang ialah berdasarkan sifat transaksinya. Menurut Suyanto (2003:45) tipe-tipe berikut segera bisa dibedakan: [4]

- Business to business (B2B)

- Business to Consumer (B2C)

- Consumer to Consumer (C2C)

- Consumer to Business (C2B)

Dan untuk journal yang kita bahas, kita menggunakan tipe $\mathrm{C} 2 \mathrm{C}$

\section{METODE}

Penelitian ini menggunakan metode Technology Acceptance Model (TAM) untuk melakukan analisis tingkat penerimaan e-commerce. TAM merupakan adaptasi dari TRA yang diperkenalkan oleh Davis pada tahun 1986. Tujuan TAM lebih dikhususkan untuk menjelaskan perilaku para pengguna komputer (computer usage behavior)[3]. TAM menggunakan TRA sebagai dasar teoritikal untuk menspesifikasi hubungan kausal antara dua kunci kepercayaan (belief) yaitu persepsi manfaat (Perceive Usefulness) dan persepsi kemudahan penggunaan (Perceieved Ease of Use). TAM jauh lebih spesifik dibandingkan dengan TRA, karena TAM ditujukan hanya untuk perilaku penggunaan teknologi komputer (Davis et.al,, 1986). Model TAM ini tidak hanya bisa untuk memprediksi, namun juga bisa menjelaskan sehingga peneliti dan para praktisi bisa mengidentifikasi mengapa suatu faktor tidak diterima dan memberikan kemungkinan langkah yang tepat[3].

Tujuan utama dari Technology Acceptance Model (TAM) sesungguhnya adalah untuk memberikan dasar langkah dari dampak suatu faktor eksternal pada kepercayaan intern (internal beliefs), sikap (attitude) dan niat (intention). TAM dirancang untuk mencapai tujuan tersebut dengan cara mengidentifikasi beberapa variabel dasar yang 
disarankan pada penelitian sebelumnya yang setuju dengan faktor-faktor yang mempengaruhi secara cognitif dan affectif pada penerimaan komputer (computer acceptance) dan menggunakan TRA sebagai dasar teoritikal untuk menentukan model hubungan variabel penelitian. TAM memposisikan dua kepercayaan (beliefs), yaitu perceive usefulness dan perceieved ease of use sebagai faktor utama perilaku penerimaan computer.[3]

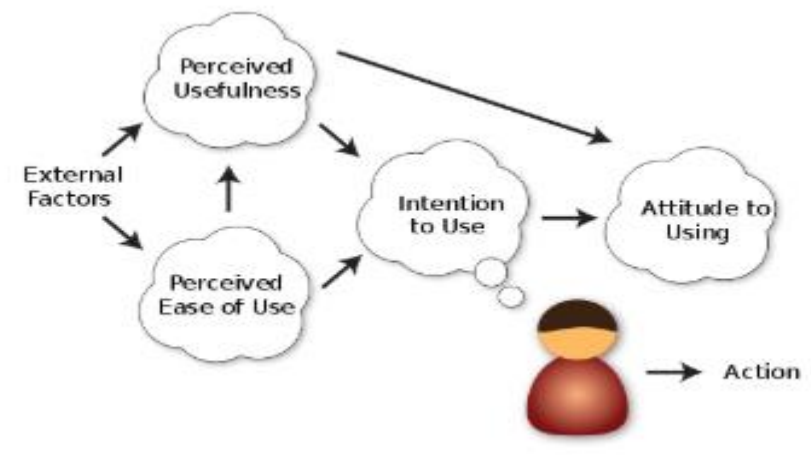

Gambar 1. Technology Acception Model (TAM)

Dalam TAM dikenal ada 5 pemahaman (Davis et. al, 1986), seperti terlihat pada gambar 1, yaitu:

1) Persepsi kemudahan penggunaan (perceived ease of use), didefinisikan sebagai sejauh mana seorang percaya bahwa menggunakan suatu teknologi akan bebas dari usaha.

2) Persepsi kegunaan (perceived usefulness), didefinisikan sebagai sejauh mana seorang percaya bahwa menggunakan suatu teknologi akan meningkatkan kinerjanya.

3) Sikap terhadap penggunaan teknologi (attitude toward using), didefinisikan sebagai evaluasi dari pemakai tentang ketertarikannya dalam menggunakan teknologi.

4) Minat perilaku menggunakan teknologi (behavioral intention to use), didefinisikan sebagai minat (keinginan) seseorang untuk melakukan perilaku tertentu.

5) Penggunaan teknologi sesungguhnya (actual technology usage), diukur dengan jumlah waktu yang digunakan untuk berinteraksi dengan teknologi dan frekuensi penggunaan teknologi tersebut.

\section{PEMBAHASAN DAN HASIL}

Dari penggumpulan data yang dilakukan, diperoleh karakteristik Responden, sebagai berikut :

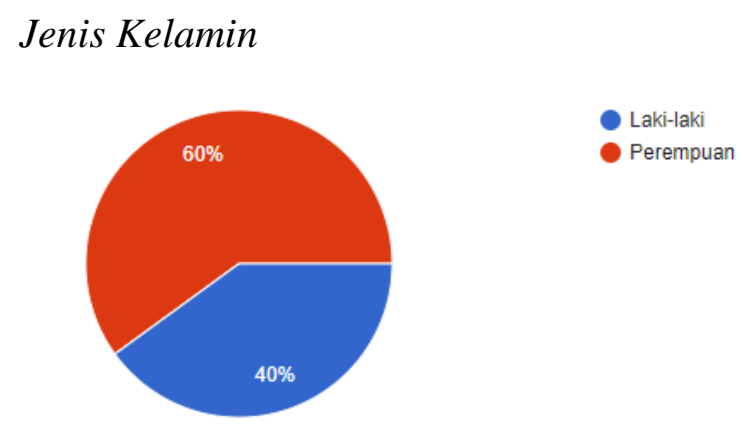

Berdasarkan penelitian terhadap 50 kuisioner, mayoritas reponden berjenis kelamin perempuan sebanyak 30 responden (60\%). Sedangkan sisanya 20 responden $(40 \%)$ berjenis kelamin laki-laki.

\section{Umur}

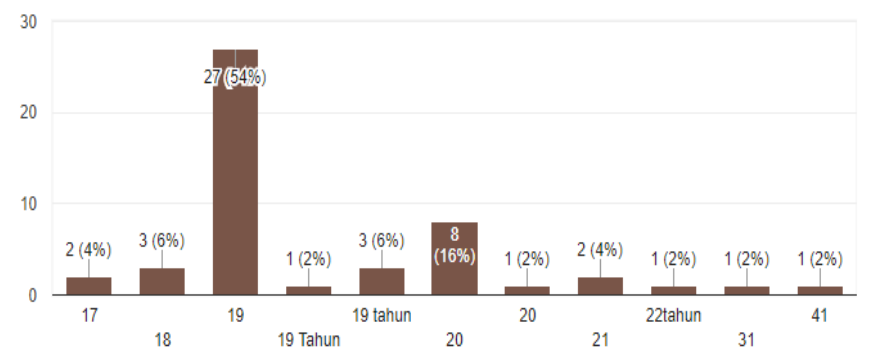

Dapat diketahui berdasarkan 50 responden, terdapat 2 orang $4 \%$ responden berusia 17 tahun, 3 orang atau $6 \%$ responden berusia 18 tahun, 31 orang atau $62 \%$ responden berusia 19 tahun, 9 orang atau $18 \%$ responden berusia 20 tahun, 2 orang atau $4 \%$ berusia 21 tahun, 1 orang atau $2 \%$ 
yang berusia 22 dan 31 tahun. Jadi mayoritas responden yaitu yang berusia 19 tahun (62\%).

\section{Berdasarkan soal kuisioner}

1. Responden: Sistem E-commerce membantu saya menjadi lebih efektif

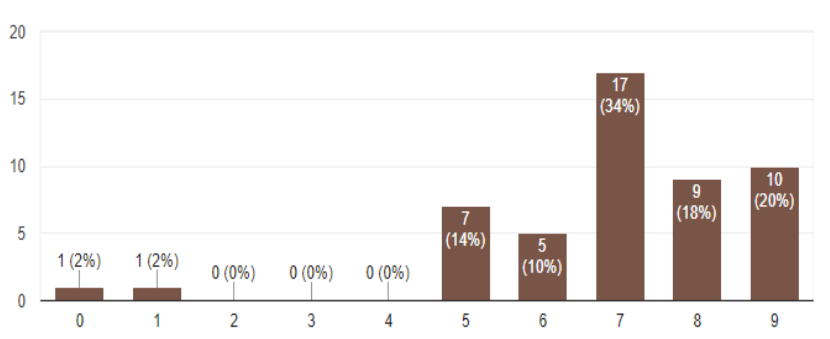

2. Responden: Sistem E-commerce membantu saya menjadi lebih produktif

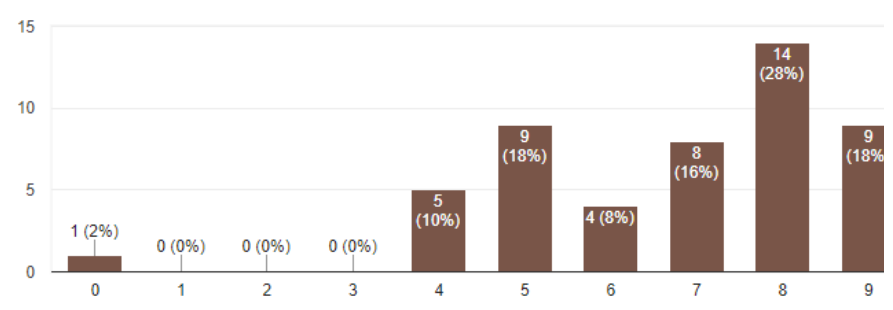

3. Responden: Informasi (seperti bantuan online, pesan di layar, dan dokumentasi lainnya) yang disediakan dengan sistem ini jelas

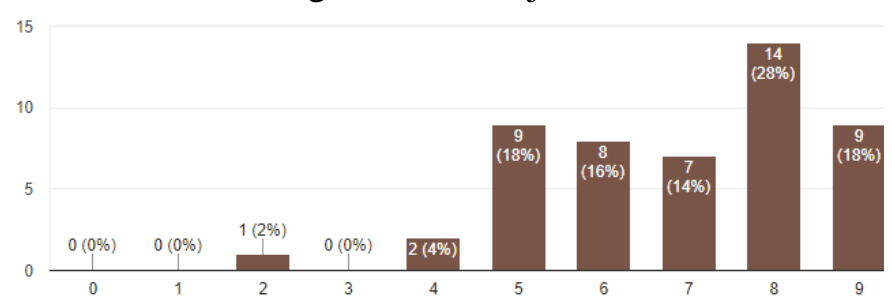

4. Responden: Sistem E-commerce mudah digunakan

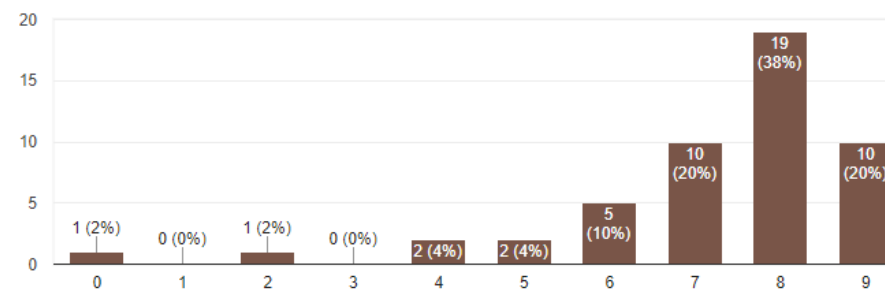

5. Responden: Penggunaan sistem E-commerce fleksibel

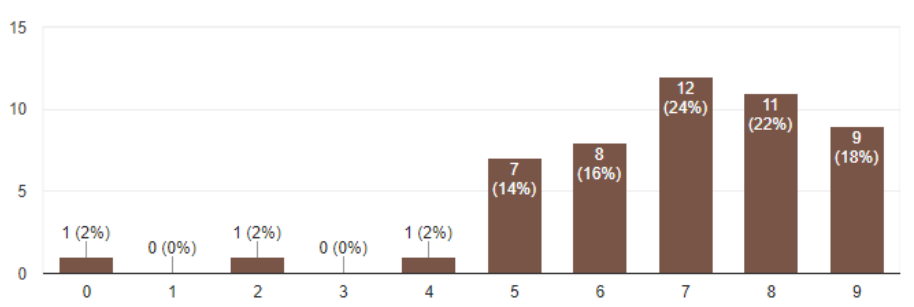

6. Responden: Saya bisa menggunakannya tanpa instruksi tertulis

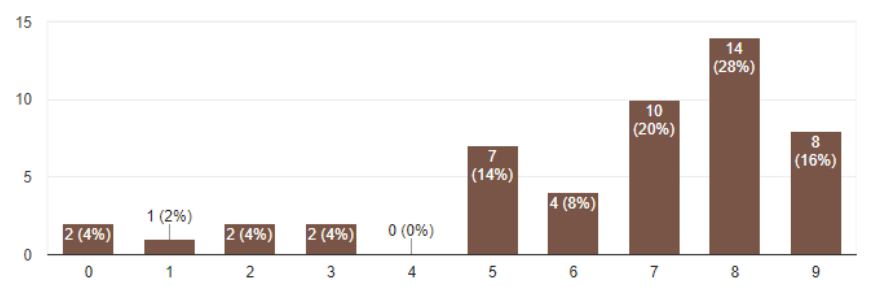

7. Responden: Saya merasa nyaman menggunakan sistem E-commerce

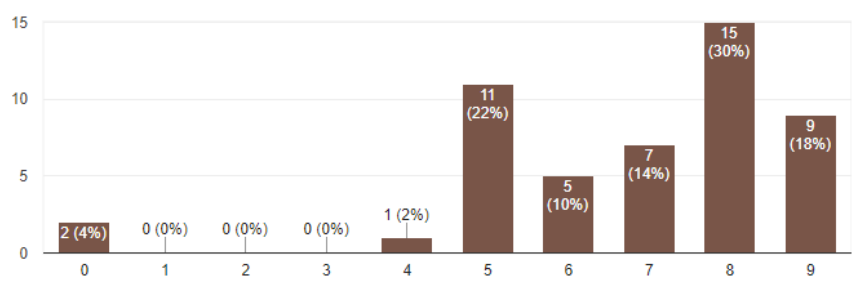

8. Responden: Saya suka menggunakan antarmuka sistem E-commerce

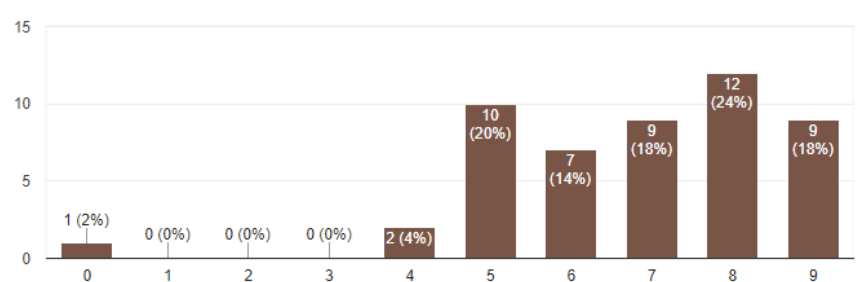

9. Responden: Sistem E-commerce memiliki semua fungsi dan kemampuan yang saya harapkan

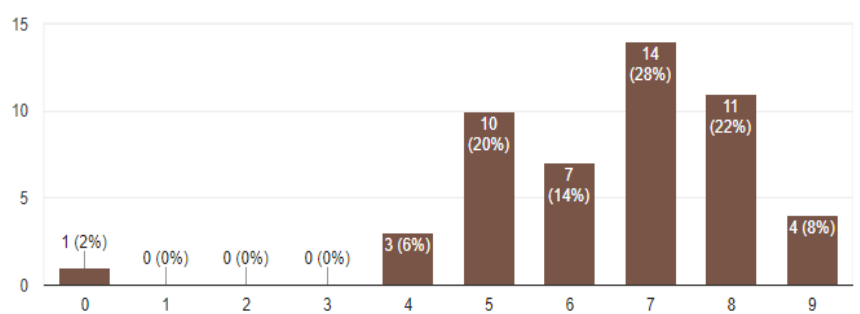


10. Responden: Secara keseluruhan, saya puas dan merasa mudah dalam menggunakan sistem Ecommerce

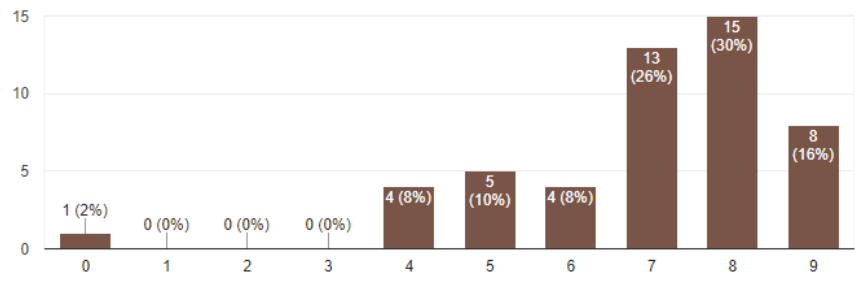

Pengaruh Kebermanfaatan (perceived usefulness)

\begin{tabular}{|c|c|c|}
\hline No & Pertanyaan & Keterangan \\
\hline 1. & Menjadi Efektif & $\begin{array}{l}17(34 \%) \text { dari } 50 \\
\text { responden } \\
\text { menyatakan setuju }\end{array}$ \\
\hline 2. & Menjadi Produktif & $\begin{array}{l}14(28 \%) \text { dari } 50 \\
\text { responden } \\
\text { menyatakan setuju }\end{array}$ \\
\hline 3. & $\begin{array}{l}\text { Informasi } \\
\text { disediakan dengan } \\
\text { jelas }\end{array}$ & $\begin{array}{l}14(28 \%) \text { dari } 50 \\
\text { responden } \\
\text { menyatakan setuju }\end{array}$ \\
\hline
\end{tabular}

Pengaruh Kemudahan (perceived ease of use)

\begin{tabular}{lll}
\hline No & Pertanyaan & Keterangan \\
\hline 1. & Mudah digunakan & $\begin{array}{l}19(38 \%) \text { dari 50 } \\
\text { responden } \\
\text { menyatakan setuju }\end{array}$ \\
2. & Fleksibel & $\begin{array}{l}12(24 \%) \text { dari 50 } \\
\text { responden } \\
\text { menyatakan setuju }\end{array}$ \\
3. & Menggunakan tanpa & $\begin{array}{l}14 \quad(28 \%) \text { dari 50 } \\
\text { responden } \\
\text { menyatakan setuju }\end{array}$ \\
& &
\end{tabular}

Sikap Terhadap Penggunaan (Attitude toward using)

\begin{tabular}{lll}
\hline No & Pertanyaan & Keterangan \\
\hline 1. & nyaman menggunakan & $15(30 \%)$ dari 50 \\
& sistem E-commerce & $\begin{array}{l}\text { responden } \\
\text { menyatakan } \\
\text { setuju }\end{array}$ \\
& & $12(24 \%)$ dari 50 \\
2. & menyukai antarmuka & responden \\
& sistem E-commerce & menyatakan \\
& & setuju \\
\hline
\end{tabular}

Minat Perilaku Pengguna (behavioral intention to use)

\begin{tabular}{|c|c|c|}
\hline No & Pertanyaan & Keterangan \\
\hline 1. & $\begin{array}{l}\text { Menyukai antarmuka } \\
\text { sistem E-commerce }\end{array}$ & $\begin{array}{l}12(24 \%) \text { dari } 50 \\
\text { responden } \\
\text { menyatakan setuju }\end{array}$ \\
\hline 2. & Menjadi Efektif & $\begin{array}{l}17(34 \%) \text { dari } 50 \\
\text { responden } \\
\text { menyatakan setuju }\end{array}$ \\
\hline 3. & Menjadi Produktif & $\begin{array}{l}14(28 \%) \text { dari } 50 \\
\text { responden } \\
\text { menyatakan setuju }\end{array}$ \\
\hline
\end{tabular}

Hasil yang didapatkan diatas telah menunjukan secara tampilan, penerimaan ecommerce telah memiliki tampilan yang baik dan cukup disenangi banyak responden. Dari sisi kegunaan, penerimaan e-commerce telah cukup memenuhi kebutuhan e-commerce pengguna walaupun masih belum signifikan. Pada sisi kemudahan, beberapa fungsi pada e-commerce telah dapat berfungsi sesuai tujuannya tetapi masih terdapat beberapa fungsi tertentu belum digunakan pengguna sesuai dengan peruntukannya sehingga masih belum cukup berguna. Sedangkan tingkat kepuasan, pengguna secara mayoritas telah menyatakan puas terhadap e-commerce sehingga dapat terus digunakan dengan baik dan kedepannya diharapkan untuk terus digunakan.

\section{KESIMPULAN}

Berdasarkan apa yang kami evaluasi dari penelitian ini, sesuai dengan data yang telah kami kumpulkan melalui kuesioner yang telah kami sebarkan bahwa pengguna Sistem E-Commerce mayoritas setuju jika sistem E-Commerce ini membantu mereka. Jadi dapat kami simpulkan bahwa penerimaan teknologi ini oleh para pengguna atau masyarakat baik. Hasil penelitian ini diharapkan dapat memberikan masukan bagi manajemen dan analis system agar memperhatikan minat,persepsi kegunaan,persepsi kemudahan dan lainnya dalam 
menerapkan dan mengembangkan system informasi berbasis e-commerce.

\section{REFERENSI}

[1] C. T. R. K. Ali Sadiyoko, "Increasing the Acceptance and On-Line Transaction of an ECommerce," Proceedings of National Seminar on Applied Technology, Science, and Arts, Vols. 2086-1931, pp. 216-221, 2014.

[2] M. A. Nugroho, "Model Penerimaan £Commerce," Jurnal Pendidikan Akuntansi Indonesia, vol. VII, no. 2, pp. 46-55, 2013.

[3] "Technology Acceptance Model (TAM)," 29 Mei 2013. [Online]. Available: http://pusattesis.com/technologyacceptance-model-tam/. [Accessed $20 \mathrm{Mei}$ 2018].

[4] J. D. Arcanggih, "Implementasi ECommerce Sebagai Media Promosi Dan Penjualan Secara Elektronik," Jurnal Administrasi Bisnis, vol. 14, no. 1, pp. 1-10, 2014.

[5] J. R. Batmetan Suyoto, J. D. C. L. Suares, "An Empirical Investigation on Customer Behavior to Adopt Mobile Commerce among the Y Generation in Indonesia", Sriwijaya International Conference On Engineering, Science \& Technology [SICEST 2016], 2016

[6] J.R. Batmetan, "Algoritma Ant Colony Optimization (ACO) untuk Pemilihan Jalur Tercepat Evakuasi Bencana Gunung Lokon Sulawesi Utara", Jurnal Teknologi Informasi-AITI, 2016, vol.13, no.2, pp 3148

[7] L. Madeso, D. R. Kabo, J. R. Batmetan, " Rancang Bangun Sistem Pakar Penentuan Status Gizi Pada Balita Menggunakan
Metode Forward Chainning", E-Jurnal UNSRIT, vol.2

[8] J. R. Batmetan, V. R. Palilingan, " Higher Education Students' Behaviour to Adopt Mobile Learning", IOP Conference Series: Materials Science and Engineering, 2018, vol. 306, Issue 1, pp. 012110 (2018)

[9] V. R. Palilingan, J. R. Batmetan, " Incident Management in Academic Information System using ITIL Framework", IOP Conference Series: Materials Science and Engineering, 2018, vol. 306, Issue 1, pp. 012110 (2018)

[10] J. R. Batmetan, A. J. Santoso, Pranowo, " A Multiple-Objective Ant Colony Algorithm for Optimizing Disaster Relief Logistics", Advanced Science Letters, 2017, vol.23, no.3, pp. 2344-2347

[11] M. L. Tompodung, F. Supit, J. R. Batmetan, " Rancang Bangun Aplikasi Sensus Penduduk Berbasis Android", Buletin Sariputra, 2017, vol.7, pp. 57-61

[12] J. R. Batmetan, " Optimasi Strategi Smart Environment Dalam Mitigasi Bencana Menggunakan Multi-Objective Aco (MoAco) Algorithm", Pasca Sarjana Magister Teknik Informatika Universitas Atma Jaya Yogyakarta, 2016 